\title{
$\therefore$ Study of Incidence of Persistent Sciatic Vein in Indian Population
}

\section{IJCRR}

Section: Healthcare

ISI Impact Factor

(2019-20): 1.628

IC Value (2019): 90.81

$\operatorname{SJIF}(2020)=7.893$

\section{Sachin Patil' ${ }^{1}$, Vaibhav Anjankar ${ }^{2}$, Ganesh Trivedi $^{3}$}

'Associate professor, Department of Anatomy, GAIMS, Bhuj, Gujarat, India; 'Associate professor, Department of Anatomy, JNMC, DMIMS,

Wardha, Maharashtra, India; ${ }^{3}$ Ex-Professor, Department of Anatomy, ANIIMS, Port Blair, A\&N.

\section{ABSTRACT}

Introduction: The sciatic vein serves as the most important collector of blood from the lower limb during the prenatal period. Sciatic veins are predominant veins of developing lower limb until $22 \mathrm{~mm}$ stage of the embryo, after which they involutes and the femoral system develops as a major venous system. Persistent sciatic vein (PSV) may be the failure of development of femoral vessels or failure in regression of sciatic vessels.

Objective: To study the incidence of persistent sciatic vein on the lower limbs and review the literature on the subject.

Methods: Fifty lower limbs from 25 cadavers preserved in formaldehyde were dissected at the department of Anatomy ANIIMS, during 2016 -2020, and the sciatic vein was observed in lower limbs.

Results: The normal anatomy of the femoral veins were found in 48 among 50 limbs (96\%). Persistent sciatic veins (PSV) were found in 2 of 50 limbs (4\%). In one of the left lower limb, PSV was $54 \mathrm{~cm}$ long, originating from vena committees of the anterior tibial artery in the anterior compartment of the leg, having communications with the popliteal vein in the popliteal fossa. The PSV in one right lower limb was $37 \mathrm{~cm}$ long, originating from a popliteal vein near the apex of the popliteal fossa, running upwards in back of thigh accompanied by sciatic nerve.

Conclusion: Sciatic vein (PSV) has been associated with patients with Klippel-Trenaunay Syndrome and in patients with recurrent varicose veins There is a high incidence of pulmonary embolism is seen in patients with PSV. Therefore, it must be investigated aiming at a better clinical or surgical management.

Key Words: Sciatic, Vein, Klippel-Trenaunay Syndrome, Phlebography, Varicose, Embryonic

\section{INTRODUCTION}

Persistent Sciatic Vein (PSV) is a very rare anatomic variation that was first described by Servelle M in 1978. The Persistent sciatic vein is an embryonic vein which may persist with or without the presence of femoral veins and its tributaries. ${ }^{1}$ The sciatic vein if present acts as the main venous channel for drainage when the femoral vein is blocked. The diagnosis of PSV was difficult by using phlebography but with the advance of Magnetic Resonance Imaging, it became easier to diagnose such cases. ${ }^{2}$

The Persistent Sciatic vein (PSV) is mainly due to defective development of venous formation during the later stage of embryogenesis. ${ }^{3}$ The structure of sciatic vein may be defective which carry a high risk of venous thromboembolism.
The lack of venous valves in a persistent sciatic vein may lead to chronic venous insufficiency. ${ }^{4}$ PSV has been associated with patients with Klippel-Trenaunay Syndrome and in patients with recurrent varicose veins. There is a high incidence of pulmonary embolism is seen in patients with PSV. Therefore, it must be investigated aiming at a better clinical or surgical management. ${ }^{5,6}$ The difficulty faced in treating patients for PSV excision is that If PSV is the only venous channel draining lower limb then it would be difficult to operate such cases in absence of alternative venous drainage from the leg. ${ }^{7}$

We studied the anatomy of lower limb veins over four years in 25 cadavers to see the incidence of Persistent sciatic veins.

\section{Corresponding Author:}

Dr. Sachin Patil, Associate Professor, Department of Anatomy, GAIMS, GK General Hospital Campus, Bhuj, Gujarat -370001, India. Phone: 9474202316; Email: drsachin6880@gmail.com

ISSN: 2231-2196 (Print) ISSN: 0975-5241 (Online)

Received: $16.07 .2020 \quad$ Revised: 21.09 .2020

Accepted: 23.10 .2020

Published: 03.03 .2021 


\section{MATERIALS AND METHODS}

This study was conducted in 50 lower limbs of 21 male and 4 female embalmed cadavers obtained from the Department of Anatomy, Andaman Nicobar islands institute of medical sciences. The study was conducted during the dissection of lower limbs for undergraduate MBBS students over four years from 2016. The limbs were dissected to study the incidence of persistent sciatic veins. After removing skin and superficial fascia, venous drainage was studied in the lower limb from thigh to foot. PSV was searched near the sciatic nerve. When PSV was found, its course, relations and tributaries were noted. The length of PSV, origin and termination was also noted with the help of measuring tape. The width of PSV was measured with the help of divider and scale. Photography was done using a CANON IXUS 95 IS digital camera. The data was collected and analysed.

\section{RESULTS}

The normal anatomy of the femoral veins was found in 48 among 50 limbs (96\%). Persistent sciatic veins (PSV) were found in 2 of 50 limbs (4\%). In one of the left lower limb, PSV was $54 \mathrm{~cm}$ long, originating from vena committees of the anterior tibial artery in the anterior compartment of the leg, having communications with the popliteal vein in the popliteal fossa, accompanies sciatic nerve in the back of the thigh, perforating adductor Magnus, receiving some tributaries from adductor muscles, finally terminating into the femoral vein (Figure 1,2). A popliteal vein was hypoplastic in this limb.

The PSV in one right lower limb was $37 \mathrm{~cm}$ long, originating from a popliteal vein near the apex of the popliteal fossa, running upwards in back of thigh accompanied by the sciatic nerve. It was piercing adductor Magnus and finally terminated into the femoral vein (Figure 3,4). A popliteal vein was hypoplastic in this limb also. Multiple small aneurysms were present throughout PSV whenever it was present.

\section{DISCUSSION}

The persistent sciatic vein (PSV) is a rare anomaly classified into three types: complete, proximal or superior PSV, or distal or inferior. ${ }^{8}$ Incomplete type PSV, the origin from the popliteal vein while termination is into the external iliac vein and extents throughout the knee to the thigh till the buttock. In proximal or superior PSV, the origin is from higher deep veins in thigh and termination into the pelvic vein. In distal or inferior PSV, it is present mainly in lower and medial portions of the thigh. ${ }^{9,10}$

The sciatic vein is the main venous channel draining the lower limb during embryonic life. During embryogenesis, the vascular endothelial growth factor and their receptors play important role in the differentiation of angioblasts in a primitive vascular plexus, with posterior remodelling and expansion, so vascular anomalies may occur during this process. ${ }^{11,12}$ Alteration in gene expression with the change in a gene sequence can be a possible cause of vascular anomalies. Hemodynamic alterations or defect of the mesoderm may play role in such venous variation. ${ }^{13}$

When our study was compared to previous studies on PSV we noted that incidence was showing a wide range from $3-51 \%$ in different studies. According to Cherry et al. out of 41 studied patients, 21 had PSV (51.22\%). All these cases were associated with Klippel-Trenaunay syndrome ${ }^{14}$.Labropoulos et al found that out of 24 cases studied, PSV was present in 3(12.5\%) cases in the American population. ${ }^{15,16}$ The study by Cardoso BB et al in brazil reported the incidence of PSV in 2(6\%) cases out of 32 total cases studied. ${ }^{17}$ According to Pompeo et al. out of 41 lower limbs were dissected and 169 phlebographies were studied. Among these total 210 lower limbs studied, 7 (3.33\%) presented with PSV. ${ }^{18}$ Table 1 shows the incidence of Persistent sciatic vein in different population studies. Detailed knowledge regarding the anatomical variations such as variations in long saphenous vein and the short saphenous vein is very important in the diagnosis and management of varicose veins. ${ }^{19}$

\section{CONCLUSION}

The sciatic vein serves as the most important collector of blood from the lower limb during the prenatal period. Sciatic veins are predominant veins of developing lower limb until $22 \mathrm{~mm}$ stage of the embryo, after which they involutes and the femoral system develops as a major venous system. The persistent sciatic vein may be the failure of development of femoral vessels or failure in regression of sciatic vessels. The PSV is an embryonic remnant rather than acquired one after any obstruction of femoral vein. The persistent sciatic vein may be associated with patients with Klippel-Trenaunay Syndrome or lead to chronic venous insufficiency in the lower limbs, therefore it must be investigated for better clinical or surgical management.

\section{ACKNOWLEDGEMENT}

Authors acknowledge the immense help received from scholars whose articles are cited and included in the references of this manuscript

\section{Conflicts of interest: None}

Source of funding: None 


\section{REFERENCES}

1. Koç T, Gilan IY, Külekçi GD, Kurtoğlu Z. Bilateral persistent sciatic vein: report of a case with developmental, histological and clinical aspects. Surg Radiol Anat 2014 Mar;36(2):189-94.

2. Trigaux JP, Vanbeers BE, Delcambre FE, de Fays FM, Schoevaerdts JC. Sciatic venous drainage demonstrated by varicography in patients with a patent deep venous drainage system. Cardiovasc Intervent Radiol 1989;12:103-106.

3. Goldhaber SZ and Bounameaux H. Pulmonary embolism and deep vein thrombosis. Lancet 2012;379:1835-1846.

4. Cowie Tn, McKellar MB, McLean N, Smith G. Unilateral congenital absence of the external iliac and femoral arteries. Br J Radiol 1960;33:520-522.

5. Arey LB. Developmental Anatomy. WB Saunders Company. $7^{\text {th }}$ Edition, 1974; 357-360.

6. Savov JD, Wassilev WA. Bilateral persistent complete sciatic artery. Clin Anat 2000;13:456-460.

7. Bastarrika G, Redondo P, Sierra A, Cano D, Martínez-Cuesta A, López-Gutiérrez JC, et al. New techniques for the evaluation and therapeutic planning of patients with Klippel-Trénaunay syndrome. J Am Acad Dermatol 2007;56:242-249.

8. Wright FW. Persistent axial or sciatic artery of the lower limb associated with hemihypertrophy. Clin Radiol 1964;15:291-292.

9. Latarjet M, Liard AR. Anatomiahumana. Paris. Médica Panamericana; 1983.

10. Youngson CG, Taylor B, Rankin R, Heimbecker RO. Persistent sciatic artery: a case report. Can J Surg 1980;23:466-467.

Table 1: Incidence of PSV in different studies

\begin{tabular}{|c|c|c|c|c|}
\hline $\begin{array}{l}\mathrm{Sr} \\
\text { No }\end{array}$ & $\begin{array}{l}\text { Author } \\
\text { (Year) }\end{array}$ & Population & $\begin{array}{l}\text { Number } \\
\text { of Cases } \\
\text { studied }\end{array}$ & $\begin{array}{l}\text { Incidence } \\
\text { of PSV }\end{array}$ \\
\hline 1 & $\begin{array}{l}\text { Cardoso et al., } \\
2010\end{array}$ & Brazilian & 32 & $2(6 \%)$ \\
\hline 2 & $\begin{array}{l}\text { Labropoulos } \\
\text { et al., } 2009\end{array}$ & American & 24 & $3(12.5 \%)$ \\
\hline 3 & $\begin{array}{l}\text { Cherry et al., } \\
1996\end{array}$ & American & 41 & $21(51.2 \%)$ \\
\hline 4 & $\begin{array}{l}\text { Pompeo et al., } \\
2003\end{array}$ & Brazilian & 210 & $7(3 \cdot 3 \%)$ \\
\hline 5 & Present study & Indian & 50 & $2(4 \%)$ \\
\hline
\end{tabular}

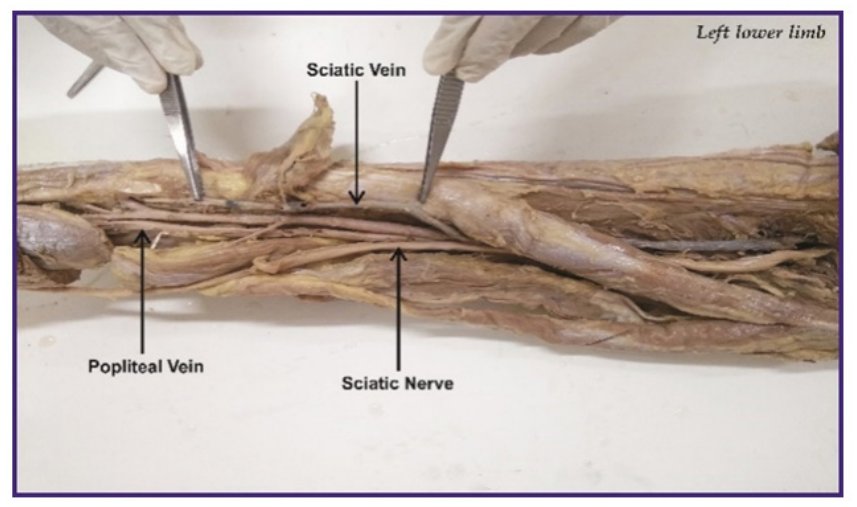

Figure 1: Persistent sciatic vein in left lower limb.
11. You CK, Rees J, Gillis DA, Steeves J. Klippel-Trenauney syndrome: a review. Can J Surg 1983;26:399-403.

12. Brantley SK, Rigdon EE, Raju S. Persistent sciatic artery: embryology, pathology and treatment. J Vasc Surg 1993;18:242248.

13. Balli R, Bertelli D. Trattado di anatomia Umana. 2. ed. Milão: Dottor Francisco Veliardi; 1924. v. III.

14. Parry DJ, Aldoon MI, Hammond RJ, Jessil PO, Weston M, Scott DJA. Persistent sciatic vein, varicose veins and lower limb hypertrophy: an usual case or discrete clinical syndrome? J Vasc Surg 2002;36:396-400.

15. Cherry KJ, Gloviczki P, Stanson AW. Persistent sciatic vein: diagnosis and treatment of a rare condition. J Vasc Surg 1996;23:490-497.

16. Labropoulos N, Tassiopoulos AK, Gasparis AP, Phillips B, Pappas PJ. Veins along the course of the sciatic nerve. J Vasc Surg 2009;49(3):690-696.

17. Cardoso BB, Alvarenga CO, Miyahara MDS, Burihan MC, Lima MR, Kuwahara MC, et al. Persistent sciatic vein. J Vasc Bras 2010;9(3):137-140.

18. Golan JF, Garrett WV, Smith BL, Talkington CM, Thompson JE.Persistent sciatic artery and vein: an unusual case. J Vasc Surg 1986;3:162-165.

19. Anupama D, Nagaraj DN, Suresh BS, Lakshmi R, Subhash P. A study of variations in the short saphenous venous system with clinical correlation. Int J Curr Res Rev 2020;5(13):29-136.

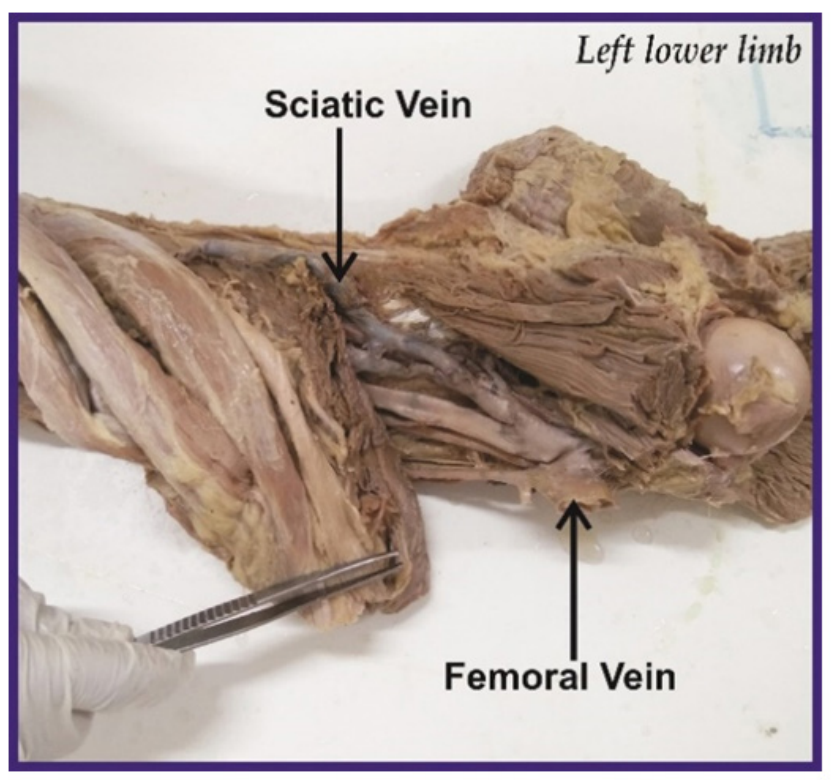

Figure 2: Termination of Persistent sciatic vein in femoral vein on left side. 


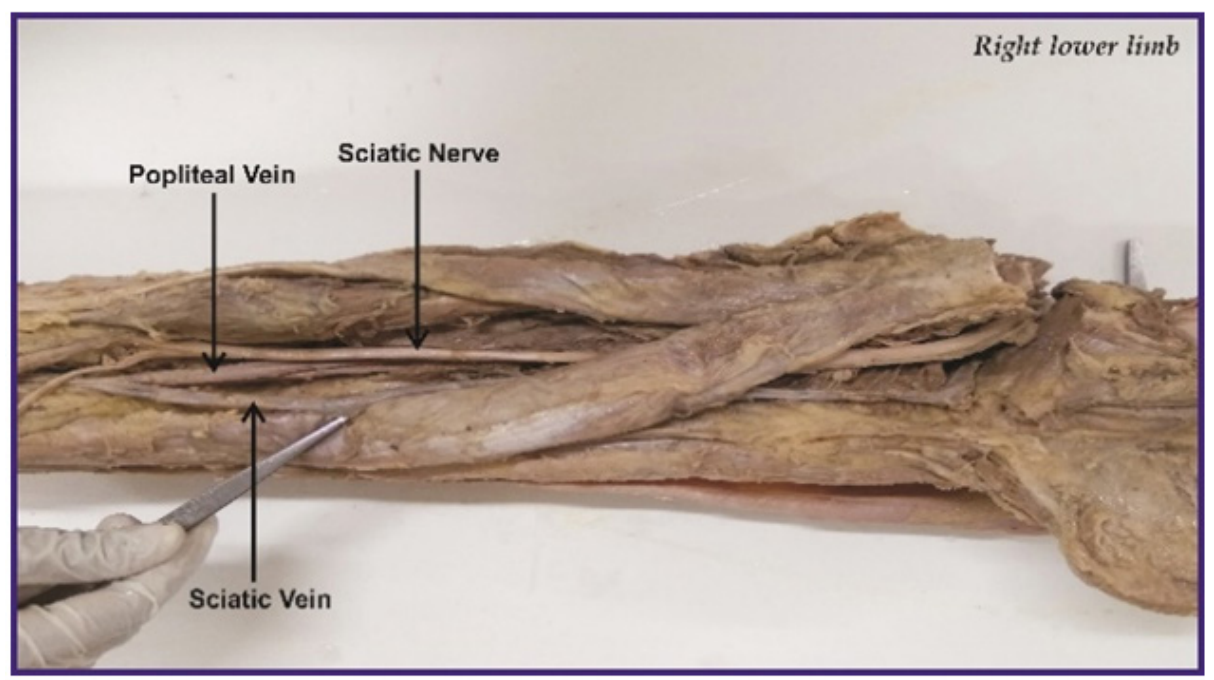

Figure 3: Persistent sciatic vein in right lower limb.

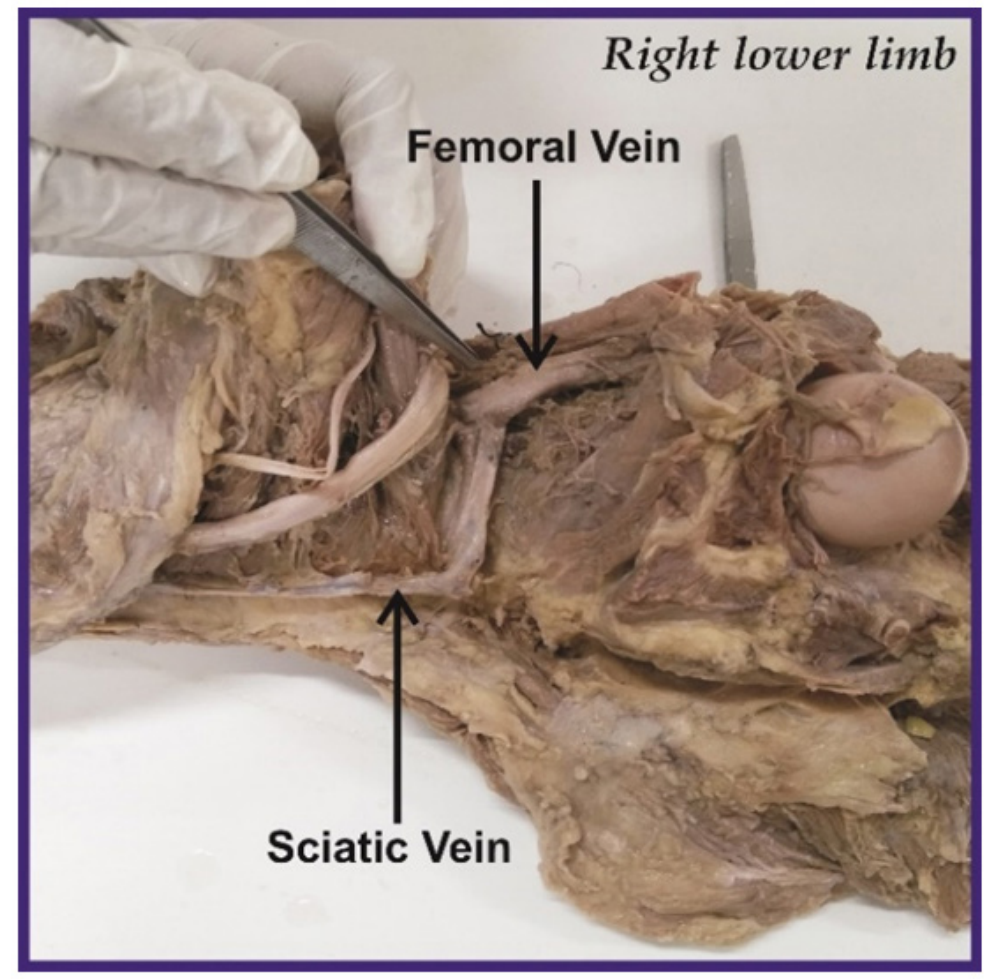

Figure 4: Termination of Persistent sciatic vein in femoral vein on right side. 